\title{
VIDA E MORTE NO MUNDO ANTIGO: A TETRARQUIA E A ÚlTIMA PERSEGUIÇÃO AOS CRISTÃOS (303 - 311).
}

\author{
Cláudio Umpierre Carlan ${ }^{1}$
}

\begin{abstract}
The present paper begins with a description of the Roman world after the Tetrarchy, with the fight for power between Constantine and, later, Licinius. We analyzed the political matters concerning the Roman world during this period. The numismatic collection stored at the Museu Histórico Nacional (National Historical Museum - MHN) in Rio de Janeiro, Brazil, served as an iconographic source to show how images were used at that time as propaganda, supporting and legitimizing the imperial rule.
\end{abstract}

Key-words

Coins; empire; iconography; power; symbol.

\section{Resumo}

O artigo começa com uma descrição do mundo romano após a Tetrarquia, com a luta pelo poder entre Constantino e, mais tarde, Licínio. Analisamos as questões políticas relativas ao mundo romano durante o período. Usando como fonte iconográfica a coleção numismática do acervo do Museu Histórico Nacional / RJ, utilizamos a imagem como uma fonte de propaganda, legitimando o poder imperial.

\section{Palavras-chave}

Moeda; império; iconografia; poder; símbolo.

\footnotetext{
1 Professor Doutor, Universidade Federal de Alfenas, Alfenas, Brasil. E-mail: carlanclaudio@gmail.com
} 


\section{Introdução}

Com a morte do Imperador Alexandre Severo, assassinado por seus soldados no ano de 235, tem início em Roma um período conhecido como a crise do século III. A crise atinge todos os níveis do Império; político, social e econômico.

Houve um primeiro momento, chamado de Anarquia Militar (235 - 268), em os imperadores eram nomeados por seus soldados, sendo assassinados logo depois. Alguns chegaram à governar poucos dias. As legiões escolhiam seus generais como governantes, na esperança de receber uma recompensa. Cada legião, cada exército era fiel ao seu líder. Quando o comandante não fazia o prometido era assassinado por seus subordinados. Segundo relatos da época, alguns imperadores eram nomeados pela manhã e assassinados poucos dias depois.

A outra fase é dos Imperadores Ilírios (268 - 284), foi caracterizada por um grupo de governantes, originários da Ilíria, atual Europa Oriental. Na tentativa de resolver os problemas administrativos e econômicos criados durante a Anarquia Militar, eles tentaram realizar uma série de reformas.

Entre os anos de 238 e 285, 19 imperadores ocuparam a púrpura. Nenhum deles conseguiu atuar de forma ativa com o Senado, colocando Roma em uma crise institucional. No meio desse caos, era necessária uma série de reformas urgentes, para salvar o Império.

\section{As Reformas de Diocleciano}

Após o assassinato de Numeriano, em 284, Diocleciano ou Caius Aurelius Valerius Diocles Diocletianus, natural de Salona, hoje Split ou Spalato, cidade e porto da Croácia, foi proclamado imperador pelas tropas. Seu pai era um liberto, originário da Dalmácia, litoral da Croácia. Para evitar um fim igual ao de seus antecessores, tratou de apoiar-se em elementos de sua confiança e do mesmo mundo social.

Com Diocleciano, tem início um dos programas de reformas mais importantes da História Romana, com o advento da restauração do Império. O Estado foi transformado em uma monarquia absoluta, em que o imperador possuía a autoridade máxima, baseada na escravidão, na servidão dos camponeses livres, na burocracia estatal e no exército. As monarquias orientais, na qual tudo que cercava o rei era sagrado, influenciou diretamente esse período. 
No ano de 286, Diocleciano inicia uma série de reformas que, por algum tempo, restaura a ordem. Inicialmente é instalada uma diarquia ao lado de Maximiano (285/286-305), amigo e colega de armas.

O sistema de diarquia é ampliado para tetrarquia. Para evitar futuras revoltas, escolhe elementos da mesma origem e camada social: Galério seu adjunto, guardara gado nos Cárpatos; Maximiano antigo colega de armas; Constâncio Cloro ajudante de armas de Maximiano. Eles e seus sucessores escolheram auxiliares de passado idêntico.

A ideia original de Diocleciano partia do princípio de que o Império era muito grande para uma só pessoa governar. Então, ele teve o bom senso de dividir o mundo romano, entre pessoas de sua confiança criando, assim, a tetrarquia. Ele achava que ninguém deveria ficar eternamente no poder. Então, criou meios para que o seu governo e de Maximiano tivessem um fim.

Assim, no sistema da Tetrarquia, os imperadores principais, Augusti, só poderiam governar durante 20 anos. Ao término desse tempo, o poder era passado aos seus auxiliares, os Césares. Esses, por sua vez, passariam à função de Augustus e escolheriam outros dois Césares.

Aliado a esses fatos, ocorreu uma inversão do eixo político. Roma passou para um segundo plano após a oficialização das novas capitais: Aquilea e Tréveres no ocidente, Sírmio e Nicomédia no oriente. Com essa divisão, foi possível produzir uma série de resultados satisfatórios.

Em 297, Galério, no baixo Danúbio, expulsa os godos. No ano seguinte, consegue uma importante vitória contra os sassânidas, ampliando a fronteira romana para o Curdistão. Diocleciano massacrou uma revolta em Alexandria, derrotando o usurpador Domicio Domiciano; Constâncio I, ou Cloro recuperou a Bretanha das mãos de Alecto; e Maximiano termina com uma rebelião na Mauritânia.

Os tetrarcas tentavam demonstrar à população que os tempos do Principado, ou seja, do apogeu do Império, estavam de volta. Não apenas uma nova ordem, mas o retorno à antiga. Num período de crises e revoltas, a união e amizade entre os governantes eram fundamentais para estabilidade de Roma.

Foram realizadas uma série de monumentos, no qual essa união é evidente. Essas obras serviam como uma espécie de propaganda política da época, representando a união e amizade a favor do Império, afinal, segundo eles mesmo, trabalhavam pela salvação do já decadente mundo romano. 
Como podemos identificar nessas cunhagens monetárias do período.
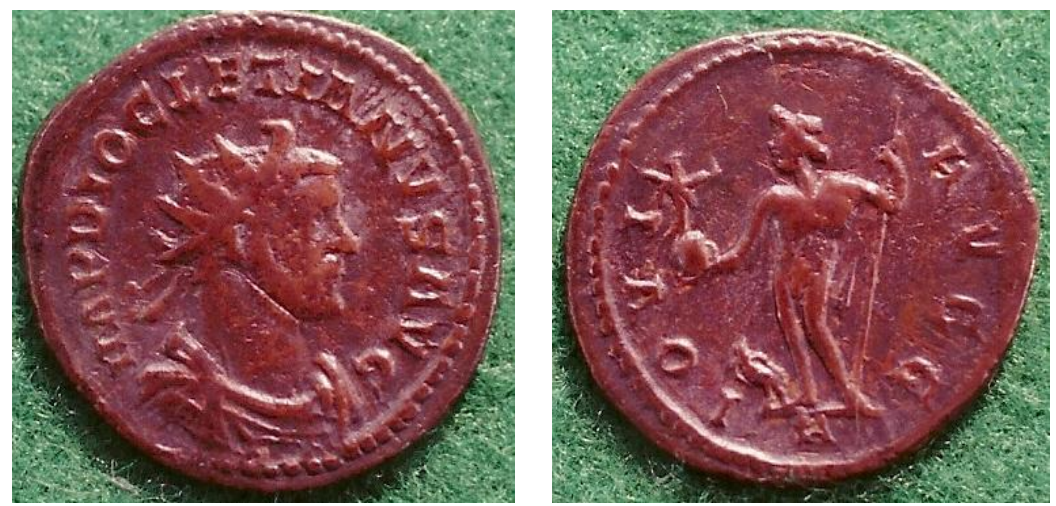

Acervo do Museu Histórico Nacional, Rio de Janeiro. Foto: Cláudio Umpierre Carlan, outubro de 2006.

Legendas:

\section{Anverso: IMP DIOCLETIANVS PF AVG}

Reverso: IOVICO AVGG

Follis de bronze cunhada durante o período da tetrarquia. Fabricada entre os anos de 304 e 305, na cidade de Alexandria. A "cara" ou anverso, representa o busto do Imperador Diocleciano, radiado, como uma coroa de raios. $\mathrm{Na}$ "coroa" ou reverso, a imagem de Júpiter, divindade suprema. Representando uma figura masculina, com globo na mão direita, símbolo da realeza e perfeição, com a imagem da Vitória, deusa alada.

Follis, foi uma amoedação de bronze, criada durante a reforma econômica a de Diocleciano, entre os anos de 294 e 295.

Durante os 20 anos da tetrarquia, Diocleciano era considerado um iuno, filho de Júpiter (Carlan: 2006, 12). 

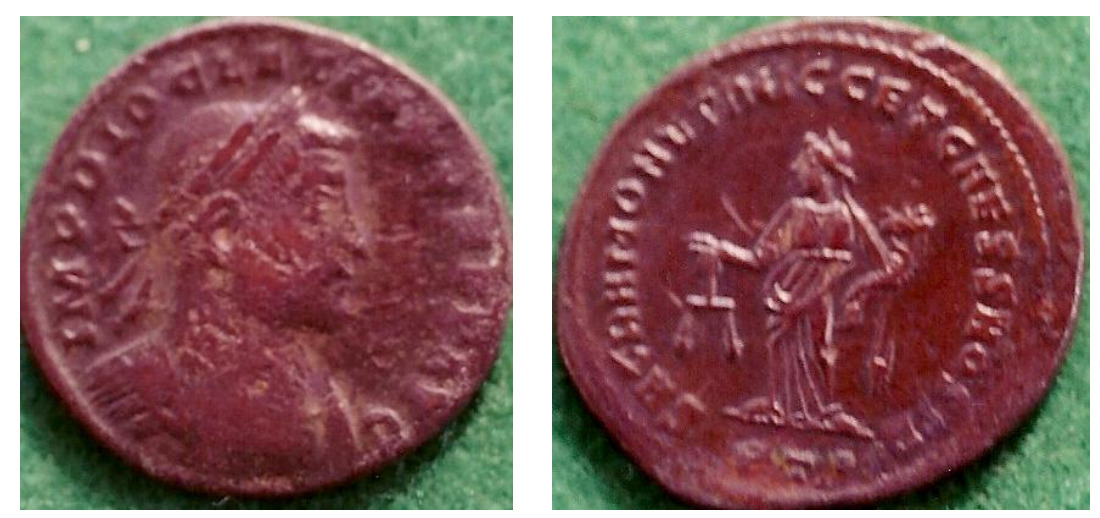

Acervo do Museu Histórico Nacional, Rio de Janeiro. Foto: Cláudio Umpierre Carlan, outubro de 2006.

Legendas:

Anverso: IMP DIOCLETIANVS PF AVG

Reverso: SACRA MONET AVGG ET CAESS NOSTR

Follis cunhado no ano 300, na primeira casa de Tréveres ou Trier. No anverso busto de Diocleciano, encouraçado e diademada. A diferença crucial vem no reverso dessa peça. Referente à tradição republicana romana. SACRA MONET, templo de Juno, local sagrado que, através da presença pombos, teria alertado aos romanos a chegada do invasor gaulês, no século IV a.C.

Dentro do padrão simbólico utilizado na Tetrarquia, nessa amoedação destacamos: Balança; justiça, prudência, cuja função corresponde à pesagem dos atos (Chevalier. Gheerbrant: 1997, 113); a cornucópia, que na tradição romana representa a felicidade e fecundidade, com abertura para cima, não para baixo, é identificada com várias divindades (Chevalier, Gherbrant: 1997, 288).

\section{A Perseguição}

Esse período de turbulência foi de suma importância para a Igreja Cristã, pois seu papel de evangelização cresceu nas províncias orientais do Império e em algumas zonas ocidentais do Mediterrâneo. Foram 50 anos de paz e prosperidade para os cristãos. Até que Diocleciano, durante o seu governo, organizou a última perseguição a eles (303-313), pondo fim nessa suposta felicidade. 
Uma mudança brusca, acerca da qual a maioria dos historiadores tem uma explicação pessoal. Mas, como não é o nosso objetivo discutir as várias correntes que analisaram esse período, ficaremos com a tradição cristã, segundo a qual Diocleciano cedeu às insistências de seu genro e César, Galério, como desculpa, acusou os cristãos de colocarem fogo no palácio imperial em Nicomédia.

O retórico cristão, Lactâncio (245 ou 250 - 325), em sua obra De Mortibus Persecutorum, narra, dentro da perspectiva cristã, esse período.

O primeiro edito de perseguição, datado do dia 23 de fevereiro de 303 , ordenava o fechamento das igrejas, a entrega das escrituras e uma ordem ao clero que fossem feitos sacrifícios aos deuses. Até esse momento, só foram afetadas as autoridades eclesiásticas, mas outro edito estendeu a obrigação do sacrifício a toda à comunidade cristã. Com a recusa dos cristãos, as autoridades militares fizeram cumprir as ordens imperiais.

Na realidade, a perseguição não foi tão terrível assim. Em alguns locais, como no Ocidente governado por Maximiano, ou nas regiões sob autoridade de Constâncio I ou Cloro, pai de Constantino, a perseguição foi mais branda.

Constâncio Cloro, por exemplo, multava os cristãos em um valor simbólico. Apenas para cumprir a ordem imperial, afinal, o valor da multa não era estipulado pelo Império. Maximiano obrigava os cristãos a entrarem no Templo de Júpiter, chegando a ponto de muitos serem carregados nos braços pelos legionários romanos, sem violência física. Uma vez lá dentro, eram libertados. Cumpriam as ordens, mas não diziam como.

No Oriente, entretanto, a perseguição foi mais violenta. A esposa e filha de Diocleciano, Prisca e Valéria, cristãs convictas, morreram durante esse período.

Passado os 20 anos de governo, os candidatos a César foram préescolhidos por Diocleciano. $\mathrm{O}$ ano 305 marcou o final da primeira tetrarquia com a renúncia dos Augusti Diocleciano e Maximinano. Dessa forma, os dois césares ascenderam à categoria de Augustus, e dois oficiais ilírios foram nomeados seus auxiliares.

A segunda tetrarquia ficou formada com: Constâncio Cloro e Severo II (ou Severo Augusto), no ocidente; Galério e Maximino Daia (ou Daza), sobrinho de Galério, no oriente. Com a exclusão dos filhos naturais, legítimos ou não, tem início uma nova guerra civil. 
O grande problema criado por essa ordem de sucessão era a situação dos filhos, legítimos ou não, dos governantes. Constantino filho de Constâncio Cloro e Helena, futura Santa Helena, e Maxêncio, filho de Maximiano, não aceitaram ser afastados do poder. O próprio Maximiano não aceitou o seu isolamento, retornando, em 306, ao cenário político.

Constâncio Cloro caiu enfermo durante uma expedição contra os pictos na Calcedônia, morrendo no ano de 306. Constantino, se encontrava a seu lado em Eboracum (atual York). Seu general, Croco, de origem germânica, e as tropas leais a seu pai, proclamaram-no imperador. Simultaneamente, o César ocidental, Severo, era proclamado augustus por Galério. Nesse mesmo ano, em Roma, Maxêncio era também proclamado imperador, e Maximiano retornava à vida pública, reclamando o título imperial.

O primeiro a cair foi Severo, traído por suas tropas, enquanto Constantino e Maximiano realizaram uma aliança. Ao final de 307 havia quatro augusti - Constantino, Maximiano, Galério, Maxêncio - e um César, Maximino Daia. Iniciando uma verdadeira guerra civil.

\section{Considerações Finais}

Um dos pontos principais das reformas que precisamos destacar é o colonato. Nesse sistema, o trabalhador rural, colono, fica preso a terra. Não é um escravo, mas também não é um trabalhador livre. Deve uma série de obrigações aos latifundiários. Ele paga uma espécie de arrendamento pelo uso de tudo que compõe a propriedade: terra, água, ferramentas, entre outras.

Em troca, o proprietário deixa que o colono fique com uma parte da produção e o protege dos invasores e salteadores. Com isso, pequenos proprietários vendem sua propriedade em troca da proteção de um grande senhor. Trata-se do início da servidão feudal, que vigorou por boa parte da Europa.

Diocleciano foi o primeiro imperador romano a abandonar Roma como capital, exercendo o governo a partir da cidade grega de Nicomédia, na Ásia Menor, atual Turquia.

O Império foi dividido em quatro regiões administrativas. Em 293, cada imperador escolheu um sucessor: Diocleciano apontou Galério e Maximiano, Constâncio Cloro. A partir de então passaram a existir quatro imperadores, dois deles com o título de Augusto (augustus) e dois com o 
título de César (caesar). Constâncio Cloro e Galério foram proclamados Césares.

Os césares eram chefes militares capazes de governar e proteger o império, adotados como filhos pelos Augustos, a quem sucederiam em caso de morte, incapacidade provocada pela velhice ou decorridos vinte anos de seus governos.

Organizou o Dominato, ou seja, uma monarquia despótica e militar, de tipo helenístico. Sob a influência de idéias orientais, o Princeps converteuse em Dominus, isto é, em amo ou governante absoluto à frente de uma grande burocracia.

Nesse sentido, o imperador tornava-se "senhor e deus" e todos que eram admitidos em sua presença eram obrigados a ajoelhar-se e beijar-lhes a ponta do manto real. Extingüiu-se, com isso, principado romano: os civis haviam sido derrotados pelos militares, e o Senado romano foi eclipsado por uma nobreza burocrática.

O descontentamento do outros herdeiros, como Constantino e Maxêncio, levou o Império a uma nova Guerra Civil.

\section{Agradecimentos}

aos amigos e colegas Pedro Paulo Abreu Funari e Glaydson José da Silva, pela oportunidade de trocarmos ideias; a Margarida Maria de Carvalho, André Leonardo Chevitarese, Paula Aranha e a Fundação de Amparo à Pesquisa do Estado de Minas Gerais (FAPEMIG)

A responsabilidade pelas ideias restringe-se ao autor.

\section{Fontes Numismáticas}

Moedas de Diocleciano. Rio de Janeiro: acervo do Museu Histórico Nacional, Medalheiro de Número 3; Lote Número: 11.

\section{Fonte Impressa}

LACTANCIO, Lucius Caecilius Firmianus. Sobre la muerte de los perseguidores. Madrid: Editorial Gredos, 2000. 


\section{Referências bibliográficas}

CARLAN, Claudio Umpierre. Poder, imagem e Arqueologia: a iconografia monetária e o exército romano.Campinas, v. 6, n. 1, p. 7-14. Disponível em http://www.unicamp.br/chaa/rhaa/downloads/Revista\%206\%20\%20artigo\%201.pdf. Acesso: 30/03/2017.

CHEVALIER, Jean. GHEERBRANT, Alain. Dicionário de Símbolos. 8a. ed. Tradução: Vera Costa e Silva, Raul de Sá Barbosa, Ângela Melim, Lúcia Melim. Rio de Janeiro: Editora José Olympio, 1997.

FUNARI, Pedro Paulo Abreu. A Vida Cotidiana na Roma Antiga. São Paulo: Annablume, 2003.

FRÈRE, Hubert. Numismática. Uma Introdução aos Métodos e a Classificação. Tradução e Adaptação: Alain Costilhes e Maria Beatriz Florenzano. São Paulo: Sociedade Numismática Brasileira, 1984.

NELI-CLÉMENT, Jocelyne. Les Beneficiarii: militares et administrateurs au service de L'Empire (I a.C - VI p.C). Maison de l' Archeologie / Université Michel de Montaigne - Bourdeaux III. Bordeaux: AUSONIUS PUBLICATIONS, 2000.

SAN VICENTE, José Ignacio. Moneda y Propaganda Politica: de Diocleciano a Constantino. Vitoria - Gasteiz: Servicio Editorial. Universidad del País Vasco / Euskal Herrico Unibertsitatea, 2003.

SILVA, Gilvan Ventura. MENDES, Norma Musco (org.). Repensando o Império Romano. Perspectiva Socioeconômica, Política e Cultural. Rio de Janeiro: Mauad Editora, 2006.

THE ROMAN IMPERIAL COINAGE. Edited by Harold Mattingly, C.H.V. Sutherland, R.A.G. Carson. V. VI, VII, VIII. London : Spink and Sons Ltda, 1983. 